\title{
SOBRE LA HERENCIA ESPIRITUAL DE EUROPA: \\ NOTAS SOBRE EL SIGNIFICADO DE LA \\ HERENCIA ESPIRITUAL DE EUROPA PARA EL \\ PROCESO DE LA UNIFICACIÓN EUROPEA
}

\author{
Manfred BUHR \\ Universidad de Berlin \\ (Traducción de José Luis López y López de Lizaga)
}

Un balance del siglo/milenio que toca a su fin no puede concluir simplemente en una mirada retrospectiva sobre el pasado, sino que también ha de tener a la vista el porvenir. Para mí, a este porvenir pertenece en primer término el proceso de unificación europea, a cuya configuración debería contribuir la filosofía. Por eso se plantea forzosamente la cuestión del significado de la herencia espiritual europea para el proceso de unificación europea. En lo que sigue quisiera aportar algunas notas sobre esta cuestión.

Nuestro presente inmediato es un tiempo de tránsito, de transformaciones bruscas, o dicho con más exactitud: un tiempo de rupturas históricas en el que las imágenes del mundo y los valores tradicionales, las orientaciones sociales, políticas y jurídicas y la política fundada en ellas ya no funcionan, y ello en todas partes, es decir, a escala mundial. Por eso nuestro presente es descrito como un tiempo de crisis y de contradicciones. En su época opinaba Hegel: "Por lo demás no es difícil ver que nuestra época es una época de nacimiento y de tránsito a un nuevo periodo".

Si esta descripción de la realidad de nuestro tiempo es adecuada, entonces suscita una cuestión de importancia decisiva para la determinación de nuestra posición y para las consecuencias que quepa extraer de ella para nuestro pensamiento y acción. La cuestión es ésta: el contenido histórico de nuestro presente, ¿significa también un final? ¿Es acaso el «fin de la historia», como se afirma 
repetidamente? ¿ $\mathrm{O}$ el "fin de la modernidad", y junto con éste el fin y la renuncia de la Ilustración y la razón? ¿El fin y la renuncia de la herencia espiritual de Europa en su totalidad?

Tengo el discurso del «fin de la historia» no sólo por problemático, sino también por un sinsentido. Y esto ya sólo porque la historia como proceso no conoce ningún fin, al menos mientras haya hombres en este mundo, en tanto que agentes de la historia. De ahí se sigue que el proceso histórico tampoco produce decisiones históricas definitivas. Quien acepta algo tal, niega el carácter procesual de la historia, cuya más noble característica es la superación y la dimensión de futuro. En primer lugar, la historia como proceso es siempre fundamentalmente alternativa y abierta hacia delante, no a voluntad ', pero abierta en fin; y en segundo lugar, por lo que respecta a su orientación o a su finalidad, no conduce a decisiones históricas definitivas.

Las rupturas históricas no involucran el fin de la historia, ni tampoco ninguna decisión histórica definitiva. Las rupturas históricas representan por un lado cesuras, movimientos progresistas y/o regresivos, estancamientos de corta o larga duración, o incluso catástrofes. Pero por otra parte, que para mí es la esencial, las rupturas históricas suponen la liberación de oportunidades, la aceleración del dinamismo del proceso histórico y la ampliación de su campo de posibilidades y alternativas. De ahí se sigue la tarea de no inmovilizar el presente, de captarlo en su apertura y pluralidad, lo cual presupone que el pasado, el presente y el futuro deben ser pensados en uno; una tarea, por lo demás, que ya Leibniz conocía, cuando escribió que el presente está preñado de futuro y cargado de historia.

\section{II}

Las rupturas históricas de nuestro presente están acompañadas por la desorientación y la falta de una visión de conjunto que se manifiestan en crisis y catástrofes sociales, políticas, institucionales, mentales e ideológicas. Pueden

1 La historia transcurre "en condiciones inmediatamente existentes, dadas y heredadas de la tradición" (Marx), en las cuales las tradiciones desempeñan una importante función. Sin embargo, no se trata de un proceso natural, sino que es un proceso alternativo y abierto hacia delante, y también un proceso que no ha sido saldado de antemano. 
ser más fuertes o más débiles en los diversos ámbitos y regiones, pero en todo caso no son el fin de la historia. Y por eso resulta frívolo hablar, a la vista del presente, de vencedores y vencidos. Todos los posicionamientos (Parteiungen) (renuncio a propósito a hablar de partidos), las facciones políticas, las agrupaciones sociales, las comunidades intelectuales, etc., son perdedores de una u otra forma, o al menos han sufrido daños, lo que se hace notar, y no en último lugar, en cierta desorientación general. El final del antagonismo Este-Oeste ha incrementado el potencial de conflictos tanto a nivel nacional como internacional, y no ha aproximado los llamados problemas globales de la humanidad a una solución, sino que en realidad los ha hecho visibles por primera vez en toda su peligrosidad. Por eso no existe el «nuevo» orden mundial tantas veces prometido; en el mejor de los casos, existe el "viejo" orden. De nuevo podría decirse con Hegel: «la masa entera de las representaciones y conceptos vigentes hasta ahora, los vínculos del mundo se han soltado y se desmoronan como quimeras" ${ }^{2}$.

Ya en 1982 Jacques D'Hondt declaraba proféticamente en su escrito «La ética y el curso del mundo": "Naturalmente, el futuro no puede demostrarse. Pero se puede recoger indicaciones de aquello a través de lo cual el futuro se anuncia (...) Un primer indicio es el sentimiento general, fortalecido por muchísimas observaciones objetivas, de que las cosas no van a seguir como están. Si se deja que el mundo siga su marcha, ya no llegará muy lejos. Las tensiones, los conflictos, la brutalidad, la absurdidad se extienden por el mundo entero, alcanzan extremos inconcebibles y avanzan hacia una ruptura inevitable" ${ }^{3}$.

Esta "ruptura inevitable» tuvo lugar entre 1989 y 1992 . O en cualquier caso así se interpretan generalmente estos ańos. $Y$ con seguridad podríamos alcanzar un acuerdo en torno a la interpretación de estos años considerándolos como una grave cesura histórica. Pero sólo puede considerárseles como cesura histórica si se tiene en cuenta que a esta ruptura histórica han precedido y sucedido otras rupturas históricas, y seguirán sucediéndole aún otras. Con esta breve observación insinúo que los años 1989-1992 no deben ser sobrevalorados. Son

2 G. W. F. HEGEL, Dokumente zu Hegels Entwicklung, hrsg. von J. Hoffmeister, Stuttgart 1936, pág. 352

3 J. D'HONDT, "Die Ethik und der Weltlauf», in: Rekonstruktion der praktischen Philosophie, hrsg. von K. O. Apel, Stuttgart 1990, pág. 59 y ss. 
un momento de un proceso que comenzó mucho antes de 1989-1992, que aún prosigue en nuestros días y al que continuaremos sujetos en los próximos ańos, si no décadas. Esto puede interpretarse como un afirmación pesimista. Pero en modo alguno es ésa mi intención. Al contrario. Precisamente el proceso histórico actual al que me refiero, marcado por las crisis y por las contradicciones, es para mi la garantía y la confirmación frente al futuro, y por consiguiente lo concibo en primer término como una situación de oportunidades que no se debe dejar pasar. Percibirla y reconocerla es, al menos para mí, el deber de la razón.

Con esto no paso por alto que a muchas personas les inquieta la sensación de que las rupturas históricas que se han producido y aún se producen eran y son muy profundas, y que en estas circunstancias es posible que hayamos estado sentados (cada uno a su modo) sobre una quimera y tal vez todavía lo estemos, una quimera cuya disolución y destrucción podría ser algo así como un final. Pero quien así piensa y, ante todo, permanece en ese pensamiento, se entrega a la desorientación autoculpable, y sobre todo pasa por alto (lo repito) que todo final señala también el camino de las oportunidades. Al menos deberíamos haber aprendido en el Antiguo Testamento que la huída de Egipto siempre permanece abierta como una posibilidad. Y tal vez deberíamos mirar también más allá del perímetro de nuestro plato favorito. En México hay un dicho conocido: nos gusta comer como los chinos, pero pensamos como los rusos. Por supuesto, este dicho también puede invertirse. Por lo que yo sé, en ninguna lengua europea tiene la palabra "crisis" el doble significado que tiene en chino. En chino «crisis» significa peligro tanto como oportunidad (Chance). Una situación crítica nunca es solamente el suelo nutricio de la decadencia, sino que siempre es al mismo tiempo el suelo materno de un nuevo brotar. Hölderlin creía que donde amenaza el peligro crece también lo salvador. Confío en lo salvador, en la fuerza del hombre y de su razón, en la solidaridad de los hombres y de la humanidad en la forma de los pueblos, para conjurar el peligro, hacerle frente y ver en él una oportunidad, tal vez la única, para el progreso del hombre hacia mejor. Ortega y Gasset decía que refleja una especie de pobreza espiritual el no estar dispuesto a ver en la derrota uno de los rostros que la vida puede adoptar.

\section{III}

Nuestro presente, que he caracterizado como una situación histórica de ruptura, necesita una orientación y reorientación que deben ir acompañadas 
de reflexión y de un pensamiento con perspectivas. En este contexto es necesaria, ante todo, la reflexión, la consulta y la consideración de la herencia espiritual de Europa, con la cual, si se la examina de cerca, hay una deuda que en buena medida no se ha saldado, y que desempeña además una función subordinada en la conciencia general. En relación con la desorientación ampliamente extendida en nuestro presente y con el proceso de unificación europea que se ha puesto en marcha, la reflexión sobre la herencia espiritual europea resulta ser de la máxima actualidad. Dicha reflexión representa en cierto modo un punto fijo en nuestra situación histórica de ruptura, capaz de orientarnos más allá del momento presente y de la que pueden surgir fundamentaciones y no meras afirmaciones, intervenciones activas y no meras adaptaciones a una situación nueva que se experimenta como inabarcable con la mirada. Así, no da la medida el momento, el hoy, sino el trabajo omniabarcante, crítico y productivo con la herencia espiritual y, de ahí, la mirada hacia el futuro. Y ello para eludir la enfermedad de la mera adaptación al curso del tiempo y asegurarnos del curso del mundo. Pero el curso del mundo exige la consideración reflexiva de la historia ${ }^{4}$, que apenas es posible sin una reflexión sobre la herencia espiritual. Por eso debe ponerse en juego la herencia espiritual de Europa liberada de todas las estrecheces de miras nacionales, conscientes o inconscientes. Cada espíritu nacional y cada tradición nacional deben ser activados y al mismo tiempo relativizados, al ponerse en relación con otras tradiciones sin que éstas deban ser por ello abandonadas.

Elementos constitutivos y contenidos de la herencia espitirual de Europa son la razón en su unidad de razón teórica y práctica, la racionalidad y la Ilustración, la universalidad, una dimensión discursiva vinculante que se apoya en la forma clásica del diálogo intersubjetivo al tiempo que la desarrolla, y que culmina en el "reino de los fines"s, el concepto universal de hombre y de humanidad, la categoría de totalidad, o idea del mundo, que incluye lo "otro" y al "otro" y los pone en relación con lo "propio" para que no sigan siendo lo "extraño" a nosotros, la consideración reflexiva de la historia y, por último, la idea de que no puede pensarse la libertad sin la igualdad. $Y$ un pensamiento inscrito en este marco debe tener presente la afirmación de Immanuel Kant de

4 CF. M. BUHR, "Philosophische Geschichtsschreibung", in: Weltbürgerkrieg und Ideologien, hrsg. von Th. Nipperdey u. A., Frankfurt am Main - Berlin 1993, pág. 404 y ss.

5 Cf. A. GARGANO, "Es ist nicht möglich, das Gute zu tun, wenn man nicht weiss, was das Gute ist", in: Europa, pág. 19 
que la razón no conoce límites para sus proyectos, así como su afirmación, profundamente humanista, de que "en el reino de los fines todo tiene o un precio o una dignidad". "En el lugar de lo que tiene un precio puede ponerse otra cosa, como su equivalente; en cambio aquello que se eleva por encima de todo precio, y por tanto no admite ningún equivalente, eso tiene dignidad». Y: “Lo que constituye la condición en la que únicamente algo puede ser fin en sí mismo, no tiene meramente un valor relativo, es decir un precio, sino un valor interno, es decir, dignidad $n$.

¿Habría de ser desoída esta advertencia de Kant en nuestra situación histórica de ruptura? ¿Y acaso no interpela ella a las oportunidades de esta situación histórica de ruptura? ¿No indica que la llamada economía libre de mercado no es suficiente, si es que la dignidad del hombre no ha de ser sólo solemnemente declarada en las Constituciones, sino realiter intocable? Esto significa, por decirlo con Hans-Dieter Klein, que hay que "crear el marco de condiciones que minimice en el mundo entero las diferencias sociales, las diferencias de distribución económica y que haga justicia a las exigencias ecológicas. Pero como todo esto sólo es posible si el pueblo soberano, más aún: el pueblo de la humanidad, así lo comprende y lo quiere, hace falta un violento trabajo de conciencian. Este trabajo de conciencia comienza con la reflexión sobre la herencia espitirual, en nuestro caso la de Europa, que ha de tornarse productiva y fructífera, y ponerse en relación con la herencia espiritual de la humanidad. Para ello no basta con que "las tradiciones de la humanidad se dejen intactas unas a otras, y no se asuma el esfuerzo de aspirar a la verdad única y común a todos, aunque sea desde diferentes puntos de partida' ${ }^{7}$.

Naturalmente, en este punto podemos preguntarnos si el trabajo de conciencia requerido no será una tarea demasiado grande, una tarea que apenas puede llevarse a cabo. Si la estimación se realiza tomando simplemente el presente inmediato, el ahora desorientado y desmesurado, además de acusador, la respuesta a esta cuestión ha de ser afirmativa. Pero la reflexión sobre la esencia espiritual de Europa incluye una visión que trasciende el ahora, exige un pensamiento que lo sobrepasa, que aúna el pasado, el presente y el futuro $\mathrm{y}$ transforma la desorientación en orientación y prescribe el objetivo que debe

6 I. KANT, Fundamentación de la metafisica de las costumbres, B 78. Cf. L. SÈVE, "Bioethik und Geld: Kommt ein Europa der Werte?», in: Europa, pág. 695 y ss.

7 H. D. KLEIN, "Dialog der Religionen und Eurozentrismus», in: Europa, pág. 441. 
conducir a una humanidad pacificada, al intercambio cultural universal y a una justicia social universal. Si el trabajo de conciencia mencionado se contempla desde este punto de vista, la cuestión planteada ensancha su horizonte y adquiere un matiz realista. Se presenta en este contexto como una oportunidad de nuestra situación histórica de ruptura y como una vereda que conduce al futuro.

\section{IV}

Hasta aquí he hablado de "Europa" sin reflexionar sobre este témino. Cuando hablo de Europa no lo hago en sentido geográfico, ni tampoco geopolítico. Algo tal traería consigo ciertas pretensiones de hegemonía. Tomo el concepto de Europa en el sentido de la tradición clásica, la de un Leibniz, un Fichte o un Hegel, es decir, como una posibilidad de la filosofía de la historia. Tal modo de proceder implica una Europa de los valores y del devenir que no puede identificarse con la "Unión Europea" ni puede permanecer aferrada al Tratado de Maastricht, aunque tiene que ver con esta otra Europa, si bien la supera incluyendo la Europa del este y del sur, y ello como sujetos y no como meros objetos, como meros ámbitos de eventual o potencial asociación o ingreso en la "Unión Europea». Para expresarlo con Xavier Tilliette: «Por consiguiente, Europa como tarea y peña de Sísifo, o Europa como utopía (...). La obra [de unificación de Europa] ha comenzado. Europa occidental, o la Europa de los comerciantes, se mantiene, y entre los llamados Doce se difuminan paulatinamente las fronteras. Un tipo de unificación política está en marcha o en proyecto, pero hasta ahora se realiza con pies de barro. La alternativa, que puede llamarse, en palabras del general De Gaulle (...), la Europa de las patrias o (...) la Europa de los cabritillos, de los entusiastas dando brincos, ha perdido mucha de su fuerza. Todo el mundo es consciente de que no basta la voluntad política para construir Europa. No puede tacharse siglos enteros de historia con un simple trazo de pluma. (...) Sin un espíritu europeo, que de momento sólo sopla muy suavemente, es impensable una política (europea) común. Es necesaria e indispensable una construcción política que, empero, no ha hallado aún su concepto (...). Dado que la división entre el este y el oeste está hoy salvada, es aconsejable incluir a Europa del este en el proceso (...). (Pues) por fin podemos concebir una Europa conforme con su historia. Sería nefasto continuar por el camino de una pequeña Europa mientras 
la escisión a medias cerrada siguiera separando del oeste a los pueblos europeos desfallecientes. La cuestión de si podremos controlar rápidamente la gigantesca cantidad de problemas que han surgido de esta circunstancia depende en su mayor parte de que contemplemos con circunspección el futuro de Europa con todos sus componentes. Por eso resulta útil lanzar una mirada sobre la historia, incluida la historia que acaba de suceder» ${ }^{8}$.

Y Hans Michael Baumgartner dice lo mismo que Xavier Tilliette cuando pregunta: "¿Puede convertirse Europa en una "casa común" (...), o cuáles serían sus supuestos políticos, culturales, religiosos y filosóficos? ¿Sobre qué podría fundarse? ¿Qué podría ser esa identidad, ese algo común que a pesar de todas las diferencias de Estados, naciones, culturas, religiones y credos fuese capaz de poner en común y vincular a los distintos pueblos y tradiciones?»?

Esta cuestión es la antítesis de las afirmaciones de los políticos europeos. Ahí tenemos la temprana manifestación de Jean Monnet, que en este sentido dice: «Si tuviera la oportunidad de comenzar otra vez la política de la unificación europea, comenzaría por la cultura». Jacques Delor completa o aclara años más tarde esta afirmación de Jean Monnet con la siguiente interrogación escéptica: «¿Quién se enamora ya de un mercado común?».

Las manifestaciones que acabo de citar podrían interpretarse como manifestaciones de escepticismo. Pero aun si subyace a ellas un cierto escepticismo, en primer término apuntan a una carencia que han mostrado los esfuerzos del pasado y del presente por la unificación de Europa, y que aún existe. Debemos hacernos conscientes de ella. Las posibilidades de suplir esta carencia no han sido nunca tan favorables como ahora ${ }^{10}$. El fundamento para ello lo han preparado los procesos de los últimos años, si no décadas, con sus rupturas históricas, sus derrotas y crisis, con su falta de orientación y sus decepciones, pero también con el súbito aumento de las exigencias y tareas, con la ampliación de las posibilidades y ocasiones. Sin un espíritu europeo, sin la fructificación de la herencia espiritual de Europa, no puede realizarse la unión europea. Pues ésta ( $y$ no es posible acentuar esto en exceso) no sólo tiene una

8 X. TIllieTte, «Europa des Geistes und der Geister», in: Europa, pág. 35 y ss. H. M.

9 H. M. BaumgarTnER, "Europa als Thema und Aufgabe der Philosophie", in: Europa, pág. 102.

10 El objetivo del libro Das gestige Erbe Europas [La herencia espiritual de Europa] es, y no en último lugar, contribuir a superar esta carencia. 
dimensión económica y política, sino asimismo, y no en menor medida, una dimensión espiritual y también (y esto no debe ser despreciado) mental. La carencia esencial que muestra el proceso de unificación de Europa consiste en no haber visto y considerado esto. Soy de la opinión de que en el futuro la política europea podrá medirse, y no en último lugar, por el grado en que tenga en cuenta la herencia espiritual y mental de Europa, el espíritu y las mentalidades europeas, y el grado en que introduzca estos factores en la política. Acometer la unificación europea con y del espíritu y las mentalidades es también imprescindible porque la Europa unida sólo puede ser una Europa de los hombres y de los pueblos, si ha de tener consistencia.

Se trata, en último término, de una Europa de los valores y no del precio, o expresado en lenguaje profano: del dinero. Se trata de una Europa que llegue a ser guardiana de la conditio humana, o acaso que llegue a serlo de nuevo. Pero esto precisamente nos ordena recurrir a la herencia espiritual y mental de Europa, que de este modo se convierte en el anticipo de la Europa a la que hay que aspirar. La herencia espiritual y mental de Europa, que ha de tornarse productiva, no sólo incluye la filosofía y las ciencias, sino también las literaturas y las artes, y también (y no en último lugar) las religiones.

Wolfgang Kluxen ha expresado de forma impresionante lo que hoy sucede en Europa: "Europa asume una nueva forma, de esto no hay duda, o no, desde luego, tras los cambios habidos en torno al año 1989. Los esfuerzos en esa dirección comenzaron hace tiempo, como muestran predominantemente los signos de la racionalización teleológica de la economía y de la autoafirmación política. La cuestión es si el resultado será algo más que una configuración federal o de bloques; si surgirá de este proceso una identidad que integre la plenitud de la tradición histórica y de las creaciones que esa tradición ha producido en el orden de las ideas y de los valores. Una "nueva» identidad, claro está, de la que podamos esperar que sea la identidad "europea» y no un fracaso histórico. No podemos pensar Europa sin los contenidos culturales que ha acumulado históricamente, y los esfuerzos para su unificación no valen la pena si no acertamos a introducir esos contenidos culturales. No podemos evitar querer el futuro como "nuestro" futuro, y esto significa ponerlo en comunicación con nuestro pasado" ${ }^{11}$.

11 W. KLUXEN, "Europas Identität und seine philosophische Erbschaft», in: Europa, pág. 177. 
Realmente es así. De otro modo, Europa sería un sinónimo de Bruselas, es decir, de la eurocracia. Pero ésta sería el principio del fin. Forma parte del proceso de unificación de Europa el que también nosotros pensemos y actuemos como europeos, como ciudadanos europeos, y no como eurócratas. El que vive como eurócrata y se da por satisfecho con eso no está en situación de pensar como europeo, y no digamos de actuar como tal ${ }^{12}$. Estoy convencido de que el camino hacia Europa y hacia el mundo no pasa por una eurocracia como la de siempre, sino sólo por la fructificación de la herencia espiritual y mental europea. Sobre todo si Europa debe estar constituida realmente por sus hombres y sus pueblos, y no por sus comerciantes y sus estados ${ }^{13}$.

\section{V}

A los fundamentos de la herencia espiritual de Europa que hemos mencionado hasta aquí de forma general se añaden otras condiciones, a saber: corrientes, tradiciones, formas y figuras de pensamiento, etc., que han de ser consideradas, o al menos recordadas si queremos asegurarnos de que esta herencia sea productiva. Quisiera citar algunas de estas condiciones, sin pretender que mi exposición sea completa.

Habría que pensar, por ejemplo, en la problemática de la tolerancia y en su contenido, aunque también habría que hacer una advertencia sobre ella. La tolerancia, que ha de practicarse hacia el prójimo y el "otro", aun si es "extraño"; la tolerancia, que rechaza el concepto de "enemigo" y sin embargo no carece de límites. Los límites de la tolerancia resultan del deber incondicional de ser racionales, de la racionalidad y la humanidad así como del concepto universal de hombre, del respeto a otras culturas, mentalidades y religiones, y finalmente de la relativización de la propia posición y del propio sistema jurídico, así como de la propia concepción del mundo. Los límites de la tolerancia han de buscarse en ese lugar del que proceden los ideologemas irracionales y la acción que resulta de ellos; el lugar donde "lo otro" se toma como "extraño" y lo "propio" se hace pasar por superior a lo "otro". La tolerancia tiene, pág. $159 \mathrm{y}$ ss.

12 Cf. E. ChITAS, "Notizen über eine Erfahrung: Der Weg zum Marxismus», in: Europa,

13 Cf. Q. RACIONERO, «Politische Aufklärung und Staatstheorie bei Leibniz», in: Europa, pág. 517 y ss. 
pues, supuestos críticos. Pero precisamente de la conciencia y la concienciación de estos supuestos críticos «se sigue la tolerancia necesaria frente a todos los horizontes de motivaciones de los hombres en tanto que agentes", como ha señalado Erich, Heintel, a quien sigo en este punto. Y continúa así Erich Heintel: «en la actual situación histórica mundial, la tolerancia incluye que no nos atribuyamos la capacidad de penetrar con la mirada en la conciencia moral del prójimo, sospechar moralmente de nuestros contemporáneos molestos (también en relación con los cambios del poder político) y en última intancia (pretendida para sí, o figurada) "dirigirlos» hasta cierto punto. Se puede y se debe dejar que las ordenaciones jurídicas consistentes en una Constitución democrática tomen sus decisiones y fallen sus juicios en su propio ámbito.

La responsabilidad frente a la propia conciencia moral (que nadie puede tener por mí) y, para los creyentes, también frente a Dios, trasciende las ordenaciones jurídicas estatales y ya en Kant conduce, en el espacio de la humanidad (prescindiendo de las doctrinas teológicas oficiales), a la distinción entre legalidad y moralidad".

Erich Heintel no se queda ahí, sino que continúa articulando las relaciones entre la tolerancia y la filosofía: "Más allá de toda tolerancia, la filosofía es capaz de conducir, en una dichosa comunidad, a eso otro que llamamos «amistad». Desde la Antigüedad, nuestra tradición distingue entre la amistad como comunidad de intereses (por ejemplo, en la política) y la amistad (philia) como un regalo personal en un vínculo recíproco sin reservas, en el que, según Matthias Claudius, podemos dejar tranquilamente que brote un prejuicio a favor del amigo. En el horizonte de motivaciones de la fe, este género de amistad, como también el humor en tanto que disposición vital, se aproxima a lo que el cristianismo llama amor (agape), ${ }^{14}$.

De este modo, hay que acentuar y practicar la necesidad de tolerancia en la convivencia humana, pero al mismo tiempo hay que salir al paso de todos los intentos de cubrir un pensamiento y una acción intolerantes bajo la apelación a la tolerancia. El consentimiento de la tolerancia intolerante conduce a la "opresión de la humanidad en el hombre", que con mucha facilidad se convierte "en el juego del tramposo o en el admirador del fanfarrón", como

14 E. HEINTEL, "Das Zisterzienserstift Zwettl als europäische Tagungsstätte», in: Europa, pág. 156 y ss. 
afirmara Johann Eberhard Erhard ya en 1793, en su Ensayo para la Ilustración de la humanidad ${ }^{15}$. Si pensamos en los medios de comunicación modernos, el alegato de Erhard resulta ser de máxima actualidad, pese a haber sido formulado hace doscientos años, y además resulta ser una indicación de que tomemos del corpus de la herencia espiritual de Europa el estímulo para responder a las cuestiones que nos oprimen en nuestro presente inmediato.

Otro fundamento de la herencia espiritual de Europa es el de la solidaridad, que se encuentra en estrecha relación con lo que hemos dicho sobre la tolerancia. No puede pensarse una sociedad sin solidaridad, y sin sociedad aquélla no funciona en la praxis. La solidaridad es un elemento capaz de refrenar los intereses particulares de los diversos grupos sociales y comprometer así a los hombres con lo general. Esto es cierto, ante todo, en el caso de la vida interior de cada sociedad o de cada comunidad política. Pero este hecho puede transferirse a las relaciones de la propia comunidad política con otras sociedades, es decir a las relaciones con otras naciones, pueblos, Estados, regiones, etc, hasta incluir a la humanidad en su totalidad. La solidaridad, pues, como un componente esencial de todas las relaciones interiores y exteriores que entabla una nación o un Estado con otras naciones u otros Estados. En relación con esto debemos rechazar la tesis de Carl Schmitt según la cual el enemigo determina la existencia del Estado o del ciudadano del Estado. Una tesis cuya resurrección celebran hoy no sólo los teóricos y los grupos sociales llamados de derechas, sino también, y no en menor medida, los teóricos y grupos sociales llamados de izquierdas, lo cual es un signo de que los tránsitos entre "derecha" e «izquierda" se han hecho muy fluidos, y de que la oposición "derechaizquierda" debe ser analizada en profundidad ${ }^{16}$.

La solidaridad es incompatible con el esquema amigo-enemigo. Este esquema siempre trae consigo una exclusión social e intelectual. La solidaridad es indivisible y debe convertirse en un medio de la política nacional e internacional. La solidaridad es un elemento básico del orden social y político de una sociedad dada. Por lo que respecta a la solidaridad, estamos más fuertemente vinculados a Rousseau que a Locke, lo cual señala las diferenciaciones en el seno de la herencia espiritual de Europa. Una sociedad que no

15 S. Colbois y A. Perrinjaquet, «Racht zur Aufklärung und Sozialrechte - Zu J. E. Erhards Theorie der Menschenrechte", in: Europa, pág. 559 y ss.

16 M. BuHR, Über die historische Vernunft und die Zukunft der Linken, Innsbruck 1992 
cuenta la solidaridad entre sus elementos constitutivos se desmembra fácilmente en antagonismos, y es dominada por intereses particulares, lo que vale igualmente mutatis mutandis para las relaciones internacionales ${ }^{17}$.

A la herencia espiritual de Europa pertenece también, y no en último lugar, el derecho de gentes, que se desarrolló a partir del encuentro de la cultura europea con otras culturas. Dejamos aquí de lado el hecho de que ese encuentro trajo consigo la esclavización o incluso el exterminio de otros pueblos, los "nativos» desde el punto de vista europeo. (Esta problemática exigiría un ensayo aparte y pertenece al capítulo "crítica y autocrítica de Europa") ${ }^{18}$. Se da la peculiar dialéctica en el seno de la herencia espiritual de Europa de que los procesos de opresión y exterminio que partieron de Europa condujeron a tradiciones e innovaciones que hoy se reconocen y aceptan, en los acontecimientos mundiales, como un bien común positivo de la humanidad. A esto pertenece también la fundamentación de la tradición del derecho de gentes, que precedió varios siglos a la aparición de la problemática de los derechos humanos y estimuló a ésta.

Sobre el derecho de gentes como un elemento esencial de la herencia espiritual europea escribe Hans Michael Baumgartner: "Entre los escenarios epocales que han determinado esencialmente la autocomprensión europea se cuenta el hecho de que Europa conquistó y sometió al Nuevo Mundo hace quinientos años, pero descubrió al hacerlo, de forma peculiar, la diversidad de las culturas. El pensamiento de la relatividad de las culturas es un pensamiento europeo. Ningún inca hubiera llegado a la idea de hacer valer el hecho de las muchas culturas frente a una pretensión universal. La tradición del derecho de gentes surgida en la costa occidental del continente europeo, en España, es la primera tradición que se hace cargo de forma racional de las culturas extranjeras y que concibe a los extranjeros como igualmente llamados por Dios y como seres dotados de una dignidad absoluta. A esta tradición hay que agradecerle el que no se pudiera continuar la expansión natural del sometimiento y la opresión. El pensamiento del derecho de gentes, la idea de un ius gentium, que determinó todos los aspecos jurídicos del Estado, no surgió predominan-

17 Sh. AVINERI, «Solidarität und Realpolitik», in: Neue Züricher Zeitung, Fernausgabe n. ${ }^{\circ}$ 34, 11-2-1994, pág. 37.

18 Cf. sobre esto las contribuciones en Europa de D. LOsurdo, A. BuRGio, J. FiLIPEC y sobre todo de E. DUSSEL. 
temente de la teoría, sino de la experiencia del mundo aneja a la expansión europea, a partir de la cual Europa se vio confrontada con el relativismo de las culturas. A través del descubrimiento de las diversas culturas se produjo un pensamiento filosófico necesario, como ya sucediera en la confrontación de Tomás de Aquino con los árabes: si las culturas son plurales, si por ejemplo el Cristianismo ha de autoafrimarse frente al Islam, si aparecen diversas corrientes espirituales de este tipo, entonces es preciso recurrir a un instrumental común para el entendimiento, la reflexión y la deliberación: la razón. Ésta no es una sustancia ni una ficción, sino esa determinada perspectiva de consideración bajo la cual puede aceptarse que todos los hombres son iguales y pueden juzgar del mismo modo. La experiencia histórica de la relatividad de las culturas da lugar forzosamente al pensamiento de la razón, y la filosofía moderna de la razón no ha llegado al mundo en cierta ocasión, de manera simplemente casual, de modo que quizás pudiese renunciarse a ella a voluntad, sino que es, antes bien, inseparable de la experiencia de la relatividad que los europeos hicieron frente a las diversas culturas de la Tierra" ${ }^{19}$.

En mi opinión, Hans Michael Baumgartner ha acertado a reflejar, en relación con la cuestión del derecho de gentes como elemento esencial de la herencia espiritual de Europa, las relaciones recíprocas entre la historia y el desarrollo de las teorías, entre la cultura europea y otras culturas, entre el Cristianismo y otras religiones, así como la significación central de la razón en estas relaciones. La razón no puede abandonarse ni dividirse en dos mitades, si no hemos de socavar o incluso renunciar absolutamente a lo que constituye el espíritu europeo. Precisamente en nuestro tiempo, la razón es imprescindible en su unidad de razón teórica y razón práctica, como perspectiva de consideración y de entendimiento, y como fundamento del encuentro con las diferentes culturas y religiones.

\section{VI}

Si hemos de investigar y describir seriamente y de la forma más amplia posible la herencia espiritual de Europa y, en relación con esto, preguntarnos

19 H. M. Baumgartner, "Europa als Thema und Aufgabe der Philosophie», in: Europa, pág. 115 y ss. 
por la especificidad del espíritu europeo, sólo podemos hacerlo si resaltamos la particularidad de la filosofía en ese espíritu. Semejante forma de proceder señala hacia el origen del espíritu europeo entre los griegos y avanza desde ese punto hacia la exigencia de un redescubrimiento y una restauración de los derechos del Logos. De ello se sigue que la tarea mencionada no puede realizarse con un concepto empírico de investigación. Al contrario, y por decirlo con Erich Heintel, hay que «mostrar de forma diferenciada y formular sistemáticamente el significado fundamental de la filosofía». Heintel señala en este contexto a Aristóteles y Kant, a la teoría y la praxis, al conocimiento y la acción, a lo verdadero y lo bueno, a la problemática estética y teológica, para continuar así: «desde este punto se puede reconocer la particularidad de la filosofía en la universitas litterarum, y afirmarla y afianzarla frente a las desmedidas pretensiones de las ciencias particulares en el sentido del concepto moderno de investigación empírica, así como frente a los doctrinarismos acríticos y las estrecheces de miras de cualquier procedencia. Hay que constatar aquí que el término "ciencia particular" representa un conjunto de ciencias que plantean en diversas «abstracciones metódicas» diversos problemas por lo que atañe a sus supuestos, y finalmente destruyen cualquier programa de "ciencia unificada». En particular, ha de mostrarse desde la filosofía fundamental que el "pluralismo" cultivado en la teoría de la verdad por parte de la "postmodernidad» es tan insostenible como cualquier tipo de mediación absurda de teoría y praxis. Sólo sobre la base de este supuesto crítico es capaz la filosofía de arribar a un concepto diferenciado del hombre en el ámbito total de la humanidad motivadora" ${ }^{20}$.

En el fondo, Heintel aborda aquí una cuestión metodológica en relación con la reflexión y la fructificación de la herencia espiritual europea para la configuración de la unidad de Europa. Lo importante es aquí, para mí, que esta tarea puede realizarse con un programa empírico de investigación en tan escasa medida como con los edictos de la llamada postmodernidad.

El complejo de la herencia espiritual de Europa implica una serie de ulteriores cuestiones metodológicas. Quisiera aludir brevemente a algunas de ellas:

Ante todo hay que dejar bien claro en este contexto que la reflexión sobre la herencia espiritual de Europa no puede acometerse sólo desde cada perspectiva 
nacional, y tampoco en primer término por las naciones europeas económicamente más fuertes. Hay que tomar la herencia espiritual de las pequeñas naciones europeas, a este respecto, tan en serio como la de las grandes naciones, y no digo "con igualdad de derechos" porque me parece que eso va de suyo. Tal como están las cosas, la herencia espiritual de las pequeñas naciones europeas habrá de abordarse incluso con más intensidad en el furuto, pues hasta ahora ha sido descuidada. Además, las naciones europeas menores han desarrollado a lo largo de los siglos una mentalidad que podrían y deberían tomar como ejemplo las naciones grandes. Pensemos simplemente en países como Finlandia o Portugal, Suiza o los Países Bajos, Polonia, o Irlanda y Austria. Pero también en el espacio de la Europa del sur.

Lo que acabamos de decir trae inmediatamente consigo la problemática del "centro" y la "periferia" en la historiografía de la filosofía, de las ideas y de las ciencias, problemática que también podría denominarse «la grandeza de los pequeños». Al mismo tiempo, con ello pasaría al orden del día la relativización de las periodizaciones usuales o habidas hasta ahora en la historia de la filosofía, de las ideas y de las ciencias, así como la cuestión de la herencia espiritual de las diversas regiones de Europa. Ésta y otras cuestiones conducirían a una geografía del espíritu europeo, que no es algo fijo sino que ha de caracterizarse en su desarrollo en el pasado y en el presente.

Una condición para ello sería dejar atrás la suposición, ampliamente extendida, de que la historia, por decirlo con Quintín Racionero ${ }^{21}$, "discurre en la forma de una calle de un solo sentido, y más aún, está estructurada conforme a una dirección definida y sin rupturas", lo cual nos aboca a una reducción de la historia ${ }^{22}$.

21 Q. Racionero, loc. cit.

22 Racionero ilustra esta reducción tomando como ejemplo la discusión "en torno al concepto polémico de postmodernidad, como si la crítica de los aspectos fundamentales de la autocomprensión contemporánea hubiera de ser contestada con una representación rígida de la Ilustración (...), cuyas rupturas internas no pueden en modo alguno poner en cuestión el sentido unitario, moralmente superior y aún inacabado del discurso de la modernidad. $O$ también algunas exposiciones actuales del hundimiento del socialismo real, como si del análisis de sus causas concretas pudiera deducirse la mayor perfección del modelo capitalista, o como si, en vista de la situación necesariamente bipolar (que ya es producto de una interpretación ideológica) se derivase inevitablemente de este hundimiento la tesis del final de los conflictos (...) y, de ahí, del final de la historia. Frente a este tipo de argumentación, me parece importante defender 
Otra cuestión sería qué sucederá con esas posibilidades y alternativas pertenecientes al marco de la herencia espiritual de Europa y que en el pasado existían, ciertamente, pero que no llegaron a realizarse. Con esta cuestión habría, por así decirlo, oro que extraer. Y un pensamiento como el de Leibniz sería, a este respecto, un rico filón. Sólo para amplios periodos pretende la historiografía hacer valer únicamente lo que en los datos históricos ("acontecimientos") ha resultado efectivo en primer plano en la historia. Pero los datos históricos sólo resultan efectivos en la historia mediante la represión, el rechazo o el sojuzgamiento de otras posibilidades. Esto significa que los campos de posibilidades de la historia dados en cada caso no se agotan en toda su plenitud, y sus alternativas no llegan a ejecutarse. A ello se oponen los intereses diversos y antagónicos de las clases, estamentos y grupos sociales. Con otras palabras: en la historia hay lo no saldado, lo olvidado, lo sepultado, lo que trasciende el espíritu de cada época, hay corrientes subterráneas, pero sobre todo hay lo no agotado. Vista así, la historia no es sólo lo pasado, sino que al mismo tiempo es también lo presente y lo futuro.

La representación de semejante visión de la historia es particularmente necesaria en una época como la nuestra, caracterizada por las rupturas históricas, porque ampliaría nuestro horizonte con posibilidades no agotadas históricamente. Sólo que el discurso actual no se mueve en este marco porque ha abandonado la forma clásica del diálogo. Continúa vinculándose (consciente o inconscientemente) a una reducción del proceso histórico. Ha llegado la hora de liberarse de este reduccionismo histórico. Pues la presente consideración histórica (pero también la política) está aún demasiado dominada, a causa de su reduccionismo histórico, por la nefasta tesis del primado de la economía sobre la política, y por un pensamiento bipolar, el cual conduce constantemente a establecer exclusiones sociales de las minorías o de individuos, y del «otro" situado en la periferia. La Alemania actual, la Alemania de nuevo "grande", es un ejemplo paradigmático de ello.

Las rupturas históricas no se perciben, pues, como ocasiones, es decir, como situaciones históricas que crean tanto espacios libres como espacios vacíos que deben ser percibidos y rellenados, si no por la política, al menos por el pensamiento. Así, vistos también desde esta aproximación más teórica

la idea de la historia como proceso contingente y abierto, cuya conclusión no está fijada de antemano por la posición dominante de algún género de representación, o, dicho de otro modo, cuyas eventuales direcciones efectuales futuras han de ser interpretadas como una consecuencia de la intervención de los agentes y no como el resultado de una fatalidad histórica impresa por sí misma en el curso de la historia". 
o metodológica, el declarado "fin de la historia» y la disolución del proceso histórico en distintas historias significa la posibilidad de introducir un nuevo discurso de carácter dialógico o iniciar un pensamiento con rasgos nuevos que no excluya al "otro" o lo deje a la puerta ${ }^{23}$.

En este contexto, la teoría de Marx, por ejemplo, sigue siendo para mí un instrumental crítico imprescindible para aproximarnos teóricamente al proceso histórico actual. Pero ello sólo con la condición de que la teoría de Marx no se tome, como por desgracia ha sucedido muchas veces, como «la clave universal de una teoría general de filosofía de la historia, cuya mayor ventaja consista en ser suprahistórica», como afirmaba el propio Marx en una carta de noviembre de $1877^{24}$. La teoría de Marx pertenece a la herencia espiritual de Europa tanto como el cristianismo, el humanismo, la Ilustración o la filosofía clásica alemana, de la que derivó su pensamiento y que confrontó con la realidad social de su tiempo.

Debo dejar la cuestión en estas pocas indicaciones. Pero ya estas indicaciones manifiestan qué medida de "trabajo de conciencia", por servirme de nuevo de este término desafiante, nos conviene y nos sale al encuentro si queremos introducir productivamente, y como intervención nuestra, la herencia espiritual europea en el proceso de unificación de Europa.

En este sentido, tal vez no sea demasiado osado decir, con Hans-Georg Gadamer, "como última consecuencia política (...) que tal vez sobreviviremos como humanidad si llegamos a aprender que no podemos simplemente explotar nuestros medios de poder y nuestras posibilidades efectuales, sino que hemos de aprender a detenernos frente al otro como otro, frente a la naturaleza tanto como frente a las culturas de los pueblos y los Estados; y que hemos de tener experiencia del otro y de los otros del mismo modo que los otros han de tenerla de nuestra identidad, para que ambas partes participen la una de la otra» ${ }^{25}$.

\section{VII}

Con estas notas he pretendido llamar la atención sobre el significado de la herencia espiritual de Europa para el proceso de unificación europea. No he

Cf. M. BuHR, “Europa und sein geistiges Erbe», in: Europa, pág. 165 y ss.

25 H. G. GADAMER, "Die Vielfalt Europas - Erbe und Zukunft», in: Europa, pág. 67 y ss. 
podido hacer otra cosa que proponer algunos estímulos. Tengo la esperanza de que la reflexión sobre la herencia espiritual de Europa que ha sido puesta en marcha tendrá éxito, en el sentido de la fructificación y la intervención. Pero también en el sentido de Immanuel Kant, quien en 1793, su escrito Sobre el tópico: "esto quizás es correcto en la teoría, pero no sirve para la praxis", en el capítulo titulado "Derecho de gentes», escribió:

"Admitiré, pues, lo siguiente: que, dado que el género humano se encuentra permanentemente eliminando obstáculos por lo que respecta a la cultura, siendo esta tarea su fin natural, se encuentra también comprometido en el progreso hacia mejor respecto del fin moral de su existencia, y que éste puede verse interrumpido en ocasiones, pero nunca será suspendido. No me es necesario probar este supuesto. El que se opone a él es quien debe probar su tesis".

Y Kant continúa en el mismo tono optimista:

"Esta esperanza en tiempos mejores, sin la cual nunca hubiera templado el corazón humano un serio deseo de hacer algo provechoso para el bien general, siempre ha ejercido también influencia sobre el trabajo de los que piensan bien (...). Ante la triste visión no tanto de los males que oprimen al género humano por causas naturales, cuanto más bien de aquellos otros que los hombres se infligen unos a otros, el ánimo empero se alegra con la perspectiva de que en el futuro las cosas podrían mejorar. Y ello sucede, ciertamente, con una benevolencia desinteresada, pues estaremos ya hace tiempo en la tumba, y no cosecharemos los frutos que en parte nosotros mismos hemos sembrado" 26 .

\section{Referencias bibliográficas}

BuHr, M. (Hrsg.), 1994, Das gestige Erbe Europas, Napoli.

BuHR, M./CHITAS, E. (Hrsg.), 1999, O Patrimonio Espiritual de Europa, Lisboa.

26 I. KANT, Sobre el tópico: "esto quizás es correcto en la teoria, pero no sirve para la praxis", A 275 y ss. 
BuHr, M./TILLIETTE, X. (Hrsg.), 1999, Penser Européen, qu'est-ce que cela veut dire?, Lisboa.

BuHR, M., ChITAS, E. y FISCHER, M. (Hrsg.), 1998, Universalismus - Universalität, Berlin/Lisboa/Salzburg.

BuHR, M. (Hrsg.), 1999, Europa und die gestige Situation der Zeit - Beiträge zum geistigen Erbe Europas, Napoli. 